\title{
INTEGRATION OF ENERGY SAVING WITH LEAN PRODUCTION IN A FOOD PROCESSING COMPANY
}

\begin{abstract}
Increasing the energy efficiency has become a key concern in manufacturing companies due to the increased energy costs and the environmental impacts. More efficient energy saving can make the most economic contribution towards solving these problems in the short run. Companies' governments are striving to identify the most effective measures to improve energy efficiency in manufacturing processes. The specific energy consumption (SEC) is a key performance indicator used to measure the energy consumed per product. Therefore, an improvement of this value contributes to decouple of economic growth from related increase of energy consumption. This paper highlights the needs of manufacturing companies for integrating energy performance in production management. This work focuses on studying the impact of implementing lean production concepts on decreasing the SEC in a food processing organization. The reduction of SEC can be achieved by increasing the total efficiency of the production line. Implementing the lean production methodology by using energy management model achieve an increase in the production output. The lean production used to eliminate all kinds of waste in production, while using the same input resources such as raw material and energy. The main source of waste found on the production line is the defective product and time waste during changeover and manual process. The achieved results showed that the SEC improved by $15.1 \%$ by reducing the lean wastes in the production line. Implementation of lean methodology has a great impact on improving the energy saving by reducing the specific energy consumption in the organization. The SEC is a key performance indicator used to measure the efficiency of a production line or a machine in relation to its production. Energy management model is useful in identifying the area of improvement and the energy saving measure.
\end{abstract}

\section{INTODUCTION}

In most organizations especially the manufacturing industry, energy is not always given the required level of attention. However, with the recent spike in energy costs all over the world and in Egypt specifically, companies have started developing and implementing methods to save energy and become more energy efficient. The SEC is defined as the relation between the total energy consumed and the total production output of the line. The SEC is an indicator of the energy efficiency of a production line, the lower the SEC, the more efficient a production line is, and that can be achieved by either decreasing the total energy consumed

\footnotetext{
${ }^{1}$ Industrial Systems Engineering Department, October University for Modern Sciences and Arts, MSA, Egypt

${ }^{2}$ General Systems Engineering Department, October University for Modern Sciences and Arts, MSA, Egypt

${ }^{3}$ Center of Excellence October University for Modern Sciences and Arts, MSA, Egypt

*E-mail: ssalaheldein@msa.edu.eg https://doi.org/10.36897/jme/142394
} 
by the line or by increasing total production output [1]. Different studies show that there is a significant potential to improve energy efficiency of $10-30 \%$ with already available technologies in manufacturing [2]. This paper implemented lean production in an Egyptian company for food production. The first step is to find the production line that has the least efficient energy wise, which was done and it was found that production line for cheese had the highest SEC. The second step was to measure the energy consumption of each machine in the production line and find the machine with the highest consumption and either find an alternative or improve it to minimize the energy consumption. However, due to the unavailability of energy consumption measurement devices on each machine, that was no longer a feasible option to consider. The alternative is to increase the total production output of the line to decrease the SEC [3]. This increase in the total production was achieved by implementing the lean methodology to reduce all kinds of waste that were present in the production process. Because of the unique characteristics of the food processing industry, the lean methodology required slight adjustments to be applied on food industries, such as taking into consideration the limitations of the raw material availability which required the company to keep a sufficient inventory [4].

\section{LITERATURE REVIEW}

\subsection{ENERGY MANAGEMENT}

The trend of the industries is thus focused on contracting with energy service providers in order to implement energy management practices for better energy efficiency. Previously, the manufacturing firms are not significantly considered the costs of energy, due to the small fraction of energy with respect to the other costs, Moreover, the lack of data in the firms about the energy management techniques led to a need to target the energy efficiency [5]. Nevertheless, challenges exist for the energy improvements such as lack of initiation, lack of information and entrepreneurs' knowledge. The increase in the energy supply leads to higher pollution. It represents $44 \%$ of the cost of the environmental degradation in Egypt. Furthermore, the industrial sector is the main energy consumer with $37 \%$ of the total consumption and $17 \%$ of employment [6].

\section{Energy management model}

Energy management can be identified as the enhancement of the energy efficiency in the processes in order to increase profitability and reach competitive positions. In this study, an efficient structure of energy management model, as recognized in Fig. 1 is guided in the first position by the commitment of the top management with effective decision making strategies [7]. For instance, an energy manager is preferable to be hired to dedicate all his work on energy management as a permanent activity and to have control over the given production schedule. The energy management model considers the following:

- Energy Auditing

Once the decision of providing a well-organized energy consumption plan is taken, energy auditing is the following step. In this step, the possible energy savings are held clear 
with the actual energy consumption of the firm. Energy auditing can be classified to three categories:

1. Data acquisition: All the required data are gathered in this area, such as amounts of energy, their end uses, types of fuel, and volume of production.

2. Energy balance sheet: The energy balance sheet consists of a tree showing all the input and output energy forms of all the processes in the production line. Also, the full description of all the processes in the production line with all the direct and indirect used machineries is acknowledged.

3. Specific energy consumption: The specific energy consumption is the energy consumed by each product according to its weight. It is estimated in terms of KWh per $\mathrm{kg}$ of product or number of products. It is also known as the energy intensity (EI), as a tool for assessing the energy efficiency. Specific energy consumption equal to total energy consumption / total produced parts [8].

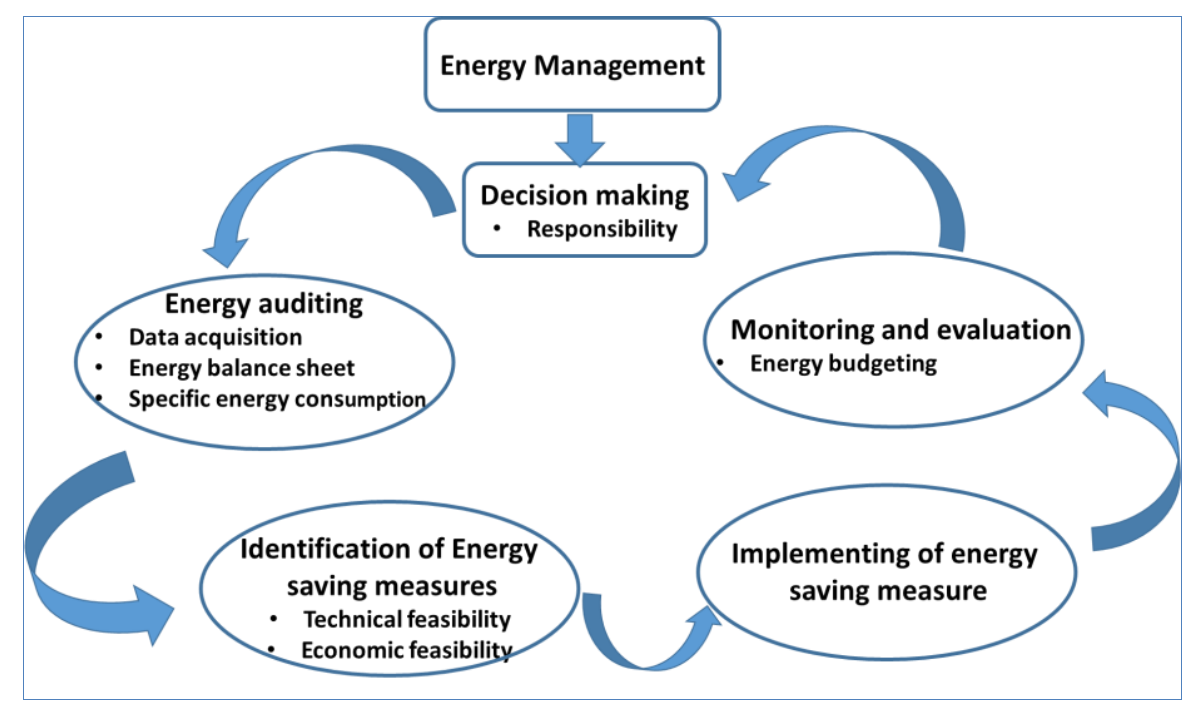

Fig. 1. Structure of Energy Management model

- Identification of energy saving measures

The identification of the energy saving methods completes the previous step. After the energy audit, the most consuming machine or area is identified. So, it is treated as the energy consumption's bottleneck. Then the technical and economic available scenarios are studied to check their feasibility. On the other hand, in the studied plant, all the machines are new and any possible solution would not be feasible due to its high cost and initial efficiency. Moreover, the lighting as well should be considered. All the lamps were replaced last year by fluorescent lamps that consume less Energy [9].

- Implementation of energy saving measures

The implementation phase should be perceived after the planning and the awareness phases after the optimal solution is found and its effects and costs were studied. Then the recommended solutions are performed with good practice in order to lead to the monitoring step. Implementing the energy saving measures would be done in coordination with the quality control department to assure the product quality is not affected. 
- Monitoring and evaluation

The monitoring phase keeps record of the implemented efficient solutions. In other words, the machines required accurate measuring devices with good control. So, the evaluation represents how far the results met the pre specified target of energy consumption. Hence, the energy management programme is a continuous cyclic process that requires in first place the data collection [9].

\section{Constraints of Energy Management Implementation}

Constraints exist in the implementation of the energy management practices. For instance, while trying to study the labors practices during the audit, they might dislike this monitoring, because they think that they are being observed or evaluated. Also, limited energy consumption data/standards/benchmarks are available for all processes in the production lines. To establish energy consumption standards /benchmarks, a data sheet should be sent to all departments in the region. However, in the studied case, they got only one response. This shows that there is a lack of interest and awareness regarding energy conservation. Though the energy management methodology was developed for entrepreneurs, it was concluded that it might be difficult for the entrepreneurs to perform the energy audit by themselves and to identify the energy conservation measures. Though their experience in the production process is an added advantage, on the other hand, it is biased when it comes to housekeeping practices or production processes. The resistance to change in suggested practices is known as "attitude change". Besides, energy management is felt as an extra workload that may be delaying further progress. So, it would be better to perform the energy audit at the initiation stage by an external consultant or an energy expert, who could also bring more experience from other industrial practices. However, the entrepreneur should get involved, so that, the energy manager could do the assessment process in a better way [7]. Maintenance operations can be effectively achieved which leads to increased machine availability, reduced waste, and improved overall efficiency.

\subsection{INTEGRATION OF LEAN PRODUCTION AND ENERGY MANAGEMENT}

Lean production supports the integration of energy consumption considerations into all activities of a company. International Organization for Standardization (ISO) is working on the new international management standard for effective energy management ISO 50001 that is planned to be launched in the final version beginning of 2011 [10]. The standard is expected to increase energy efficiency in industrial, commercial, and institutional facilities [11]. Traditionally lean manufacturing is concerned with eliminating wastes in resources such as raw material, and machine time, but not energy because it does not contribute a significant amount of the total cost. However, due to the recent increase in energy costs and the environmental concerns regarding the excessive use of energy, manufacturers began to recognize the importance of being energy efficient. Previous case studies performed on various companies revealed that the implementation of lean manufacturing results in lower costs and a general resistance to the instability in energy prices [12]. Furthermore, the U.S. Environmental Protection Agency (EPA) conducted a pilot program and according to it the excessive energy consumption should be treated as an eight waste type in lean manufacturing. 
Companies that implement lean practices achieve increased energy efficiency as well since the energy wastes are hidden by the other seven wastes. In other words, reducing changeover and failure times, and increasing throughput rate and quality, both will impact positively on energy efficiency. The seven wastes and the tools used to eliminate them are shown in Table 1.

Table 1. Types of waste and lean countermeasures

\begin{tabular}{|l|l|l|}
\hline \multicolumn{1}{|c|}{ Waste category } & \multicolumn{1}{|c|}{ Example } & \multicolumn{1}{c|}{ Countermeasure/lean technique } \\
\hline Defects & Defective products & $\begin{array}{l}\text { Promote first time through (FTT) } \\
\text { Performance criteria }\end{array}$ \\
\hline Transportation & $\begin{array}{l}\text { Space for repair and rework } \\
\text { Labour that handles items } \\
\text { Transportation equipment }\end{array}$ & $\begin{array}{l}\text { Utilize standard work } \\
\text { Layout kaizen } \\
\text { Cellular manufacturing }\end{array}$ \\
\hline Motion & Unnecessary movements, steps & $\begin{array}{l}\text { Work study } \\
\text { 5S }\end{array}$ \\
\hline Waiting & $\begin{array}{l}\text { Space for queues Production } \\
\text { of obsolete products }\end{array}$ & $\begin{array}{l}\text { Line Balancing } \\
\text { Kanban (pull production) } \\
\text { SMED (single minute exchange of die) }\end{array}$ \\
\hline Inventory & $\begin{array}{l}\text { Storage space } \\
\text { Warehouse up-keeping } \\
\text { Warehouse staff }\end{array}$ & $\begin{array}{l}\text { Kanban } \\
\text { One-piece flow }\end{array}$ \\
\hline Unnecessary processing & $\begin{array}{l}\text { Over sensitive measurement or control } \\
\text { Counting parts }\end{array}$ & $\begin{array}{l}\text { Relocation/redesign of tools and equipment } \\
\text { 5S }\end{array}$ \\
\hline Overproduction & $\begin{array}{l}\text { Operations to product } \\
\text { the unnecessary products }\end{array}$ & $\begin{array}{l}\text { Kanban } \\
\text { SMED }\end{array}$ \\
\hline
\end{tabular}

The lean tools shown in Table 1 that can be used as a countermeasure to the seven wastes will have a positive effect on energy consumption [13], for example:

- Pull system: A pull production system is to let the customer pull the demand in terms of the amount of material and the time and location of delivery. This leads to a reduction in inventories and work in process. The reduction of inventory will result in decreased storage area costs, cooling or lighting costs, and transportation costs, and consequently, decrease energy.

- Manufacturing cell: In lean manufacturing, the equipment and machines are arranged in an order that allows for a smooth flow of the material with minimum transportation. In other words, Parts that have similar operations or use the same raw material are positioned close to each other. This leads to a reduction in the amount of energy used during the production process by minimizing the transportation and delays.

- SMED: Single Minute Exchange of Die is used to reduce the setup or changeover time of a machine or a process which increases the production time. A side effect of SMED is a reduction of energy costs associated with the decrease in transportation and labor due to the optimization of the changeover tasks. Scrap that is produced during setup processes is also decreased which results in a decrease in the raw material waste and the energy used to rework that scrap.

- Total productive maintenance: TPM is used to improve the quality of the equipment and the overall equipment efficiencies. TPM results in increased machine life, 
reduced downtime, and reduced machine breakdowns [14]. That is done by training employees to spot energy wastes and report them.

- Standard work: The goal of standard work is to reduce the variability and introduce the best possible method of performing the work. The reduced variability results in a decrease of the energy during the production process. The reduction in energy consumption can also be achieved if the procedures each worker performs at his station incorporate energy reduction best practices.

- 5S: 5S aims to achieve and sustain a cleaner and more organized workplace. A disorganized workplace will be harder to clean and will require more labor/transpor-tation and consequently, more energy.

- Visual Control: Providing visual indicators for the workers and managers so they could identify the goals and current status of the workplace with ease. Such indicators include energy goals and usage so the staff could be more energy conscious, and signs to remind the workers to turn the lights or the machines off once they are finished.

- Mistake-Proofing (Poka-Yoke): Used to stop errors from occurring in the first place, and to immediately identify a defective product. An example is occupancy sensors which powers down equipment that are not in use. This results in decreased energy consumption.

Implementing lean and green concepts at the same time leads to an optimized output. This is perfectly achieved by reducing the lead times, improving the value added elements and decreasing the carbon footprints. The combination enhances better use of available resources. Thus, a significant increase in productivity is clear, in addition to a decrease in the costs that would not have been achieved by implementing of only one concept. Nevertheless, waste elimination by the lean concepts leads to a focus on the environmental performance [15]. To conclude, the benefits of the lean and green integrations present a high potential. Moreover, the decrease in the seven lean wastes points out a reduction in the input resources and in the environmental wastes. The integration also leads to better firm performance as a whole. In other words, the value of the company as perceived by a financial point of view (price of the stock, book value, and return on equity) improves. Thus, the relationship is demonstrated by the fact that lean pushes green due to the waste elimination concept. The consequences will then be proven in a better environmental performance [2]. The lean wastes such as overproduction, transportation, and quality defects have a great impact on energy consumption; therefore, if these wastes are eliminated or decreased, energy efficiency will increase [16]. The implementation of lean practices in the food processing industry may pose a challenge due to the unique characteristics that distinguish it from other discrete manufacturing industries [17]. Three examples of these characteristics developed by [18]:

1. Strict regulations due to political reasons, since it is critical that a supply of safe, affordable, and sufficient food be maintained.

2. The large batch sizes make the availability of products, reliability of supply chains, and the price competiveness critical to success.

3. Complexity of the production process, since companies have to launch new products to stay competitive in a market where customers are tempted to try new products, which further complicates the production process. In other words, the high perishability of the products, complex operations, variable availability of raw 
material, and erratic demand are all constraints imposed on the implementation of lean in the food industry.

This does not mean that lean cannot be implemented within the food processing industry; on the contrary it means that it should be implemented with increased care while considering all of the constraints attached. For example, in a case study performed by [19] at a bakeries manufacturing company, it was proved that lean tools such as SMED, 5S, and total productive maintenance can be effectively implemented.

Also implementation of lean tools fulfills in improving machine availability, reduced waste, and improved overall quality [20]. After surveying the literature, it was concluded that the SEC indicator is allowed to measure how efficient a process is relative to its production output. Moreover, it was concluded that the seven wastes discussed in the lean production methodology can have adverse effects on the energy efficiency of a process. Therefore, integrating lean management with energy saving are developed by eliminating the lean wastes which lead to increase in the total production output which would in turn decrease the SEC.

\section{DATA COLLECTION AND ANALYSIS}

The collected data focused on investigation of the current state of energy consumption on all production lines. The study focused on the production line which has the highest energy consumption. Then calculate the SEC for that line. The implementation of lean production concepts will take place in the production line to decrease all kinds of waste then compare the results to find the energy saving.

\subsection{THE INVESTIGATION STUDY CURRENT ENERGY STATE}

The manufacturing plant consists of four production lines; Line 19 produces bakeries, Line 20 produces juice, Line 21 produces milk, Line 22 produces cheeses. Due to the rising energy costs, the management implied it would be beneficial if the production lines are more energy efficient. Therefore, a deeper study was conducted over the energy consumption of the entire production lines. The main resources used in the production line are natural gas, electricity and water. Water is mainly used to clean the machines and the trays during the changeover times. Natural gas is used for heating. Electricity is used for lighting, cooling, and in all the other processes in the production lines. Thus, electricity is the most used resource in the production.

As shown in Fig. 2 the electricity costs outweigh the costs of the other resources, with their rising from January to October. Moreover, it continues to increase due to the increase in the prices. This figure is done by analyzing all the energy bills such as electricity, natural gas and water. After gathering this data, all the production data of the production lines are collected as well. Thus, the cost of each type of the three energy sources per ton of production was calculated and shown in the Fig. 2. The electricity costs increased from 
(0.435 to 0.52 ) LE/KWh during one year. The natural gas augmented from (38.7 to 79.6 ) LE/MMBTU during one year. However, the water cost is slightly increase, equals to 5.77 LE/M3.

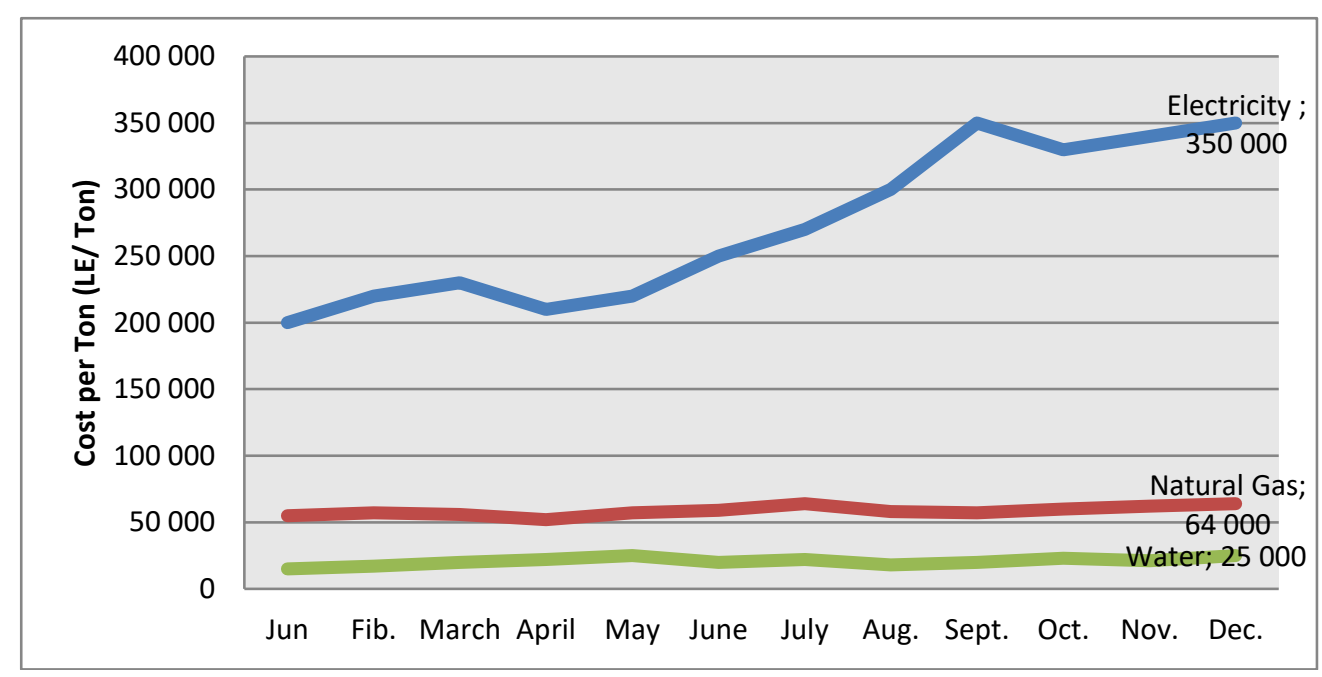

Fig. 2. Different Energy Costs per ton of production

Since electricity is the most used resource, the basic electricity saving measures was identified. Such measures include replacing the lamps into LEDs for a more efficient lighting system [8]. Since the production line operated on a 20 hours per day, and for 20 days per month, the lighting system consumed a significant amount of electricity. For that reason, electricity saving measures such as replacing the ceiling with a glass ceiling and using daylight instead of the installed lighting system were suggested but found to be inapplicable due to the heavy load of the utilities on the roof which the glass wouldn't withstand. Furthermore, such a measure would lead to an increase in the line temperature which isn't ergonomically sound. Also, since the machines were relatively new, the depreciation effects still have not taken place and therefore replacing the machines with more efficient ones was not feasible. As concluded, the electricity is the most consumed energy resource in the studied plant, so the following energy audit will focus on it.

\subsection{ENERGY AUDIT}

Since the basic electricity saving measures was either already implemented or not feasible as an option, a more detailed energy audit was conducted. The actual energy consumptions are gathered. The energy consumptions include all the four working production lines with their utilities. Due to the lack of production lines energy meters, an analysis of the number and type of machines over the lines with the utilities of each line was achieved. This analysis led to an estimation of the monthly electricity consumption of each line as shown in Table 2. The energy consumption of line 22 has the largest percentage with $35.1 \%$. This energy consumption is important in calculating the SEC of the line. 
Table 2. Consumption of electricity for each line per Month

\begin{tabular}{|l|c|c|c|c|}
\cline { 2 - 5 } \multicolumn{1}{c|}{} & Line 19 & Line 20 & Line 21 & Line 22 \\
\hline Consumption $($ KWh) & 244,398 & 151,245 & 124,384 & 281,038 \\
\hline Percentage & $30.5 \%$ & $18.9 \%$ & $15.5 \%$ & $35.1 \%$ \\
\hline
\end{tabular}

\subsection{SPECIFIC ENERGY CONSUMPTION (SEC)}

According to the literature survey, the SEC or energy intensity (EI) is one of the key performance indicators used to measure the energy efficiency of a production line. SEC is the ratio between the total energy consumed in a production line in $\mathrm{kW}$ and the total produced output in tons. The SEC was calculated for each of the four lines, in order to find the least efficient line and further investigate it for improvement opportunities. The historical acquired data of the different productions in tons of the four production lines are presented in Table 3. The SEC is calculated for each production line as shown in Table 4, and envisaged by the histogram in Fig. 3. The achieved results from Tables 3 and 4 showed that, the Line 22 has the highest SEC, and it is the most critical production line and will be focused on the possible improvements. Additionally, it can be seen as the least efficient and consecutively, the cost of the energy overheads will be the highest among the rest of the products. The SEC is a useful indicator as it shows where improvements would be more beneficial.

Table 3. Production per month for each Line (Tons)

\begin{tabular}{|l|c|c|c|c|c|c|c|c|c|c|c|c|c|}
\cline { 2 - 15 } \multicolumn{1}{c|}{} & \multicolumn{10}{c|}{ Production (Ton) } \\
\cline { 2 - 15 } & Jan & Feb & March & April & May & June & July & Aug & Sept & Oct & Nov & Dec & Average \\
\hline Line 19 & 1421 & 1416 & 1311 & 1343 & 1384 & 1412 & 1389 & 1423 & 1398 & 1385 & 1312 & 1322 & 1376.3 \\
\hline Line 20 & 915 & 878 & 712 & 789 & 752 & 698 & 714 & 802 & 697 & 781 & 769 & 781 & 774.0 \\
\hline Line 21 & 1299 & 1287 & 1296 & 1301 & 1292 & 1301 & 1298 & 1265 & 1321 & 1296 & 1255 & 1297 & 1292.3 \\
\hline Line 22 & 1258 & 1302 & 1286 & 1275 & 1285 & 1284 & 1287 & 1265 & 1279 & 1245 & 1251 & 1231 & 1270.7 \\
\hline
\end{tabular}

Table 4. Specific energy consumptions for each production line (kWh/Ton)

\begin{tabular}{|l|c|c|c|c|c|c|c|c|c|c|c|c|c|}
\cline { 2 - 16 } \multicolumn{1}{c|}{} & \multicolumn{10}{c|}{ SEC (KWh/Ton) } \\
\cline { 2 - 15 } \multicolumn{1}{c|}{} & Jan & Feb & March & April & May & June & July & Aug & Sept & Oct & Nov & Dec & Average \\
\hline Line 19 & 172.0 & 172.6 & 186.4 & 182.0 & 176.6 & 173.1 & 176.0 & 171.7 & 174.8 & 176.5 & 186.3 & 184.9 & 177.7 \\
\hline Line 20 & 165.3 & 172.3 & 212.4 & 191.7 & 201.1 & 216.7 & 211.8 & 188.6 & 217.0 & 193.7 & 196.7 & 193.7 & 196.7 \\
\hline Line 21 & 95.8 & 96.6 & 96.0 & 95.6 & 96.3 & 95.6 & 95.8 & 98.3 & 94.2 & 96.0 & 99.1 & 95.9 & 96.3 \\
\hline Line 22 & 223.4 & 215.9 & 218.5 & 220.4 & 218.7 & 218.9 & 218.4 & 222.2 & 219.7 & 225.7 & 224.7 & 228.3 & 221.2 \\
\hline
\end{tabular}

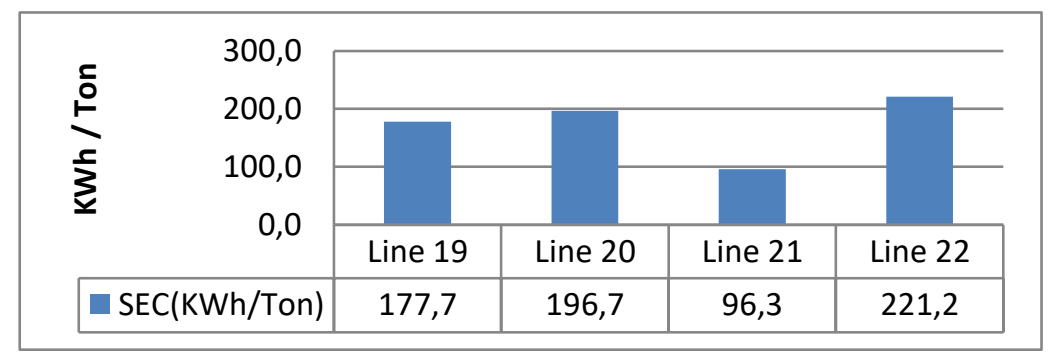

Fig. 3. Specific energy consumption for each production line 


\section{Energy Audit Constraints}

Due to the unavailability of energy meters or loggers for individual machines in each line, a detailed energy audit on such a level was not feasible. Therefore, the most detailed level possible is on an individual line level. Generally, the energy audit should go further till the machines level improvement. For instance, all the machines in all the production lines in the facility are supported by motors so a change into more efficient motors for the whole plant might be an opportunity however it is not feasible. Moreover, the availability of buying specific energy meters to measure the energy consumption for each machine but it is costs more. Thus, this analysis will be centered on the potential of reducing the SEC in the Line 22 by increasing its overall production and reducing the waste and defects.

\subsection{IMPLEMENTATION OF LEAN PRODUCTION SYSTEM}

The chosen production line 22 is evaluated to find areas of improvement from a lean point of view. Furthermore, the seven lean wastes are identified at the line and inspected according to the concept of Gemba Walk [21], additionally, multiple lean tools were used such as the value stream mapping of the current state [22], the overall equipment efficiency of the individual machines, and SMED methodology.

\section{Line Process Description}

The production line 22 produces cheese in one $\mathrm{kg}$ with many recipes. The production line is semi-automated production line, which means it can run automatically as long as the raw materials are provided at the first stage, and the second stage is manually by aid of labors as shown in Fig. 4. The production line consists of Tetra Pak unit, conveyor, strapping machine, and pallet. The process begins with the workers moving the raw material from the storage room containers into Tetra Pak unit which produce the cheese and put it in the packs and provide it to the conveyor. The production line contains six labors; four labors for collecting every six individual cheese packs into cardboard, one labor transport the cardboard into strapping machine. The last labor transports the strapped cardboard into the pallet.

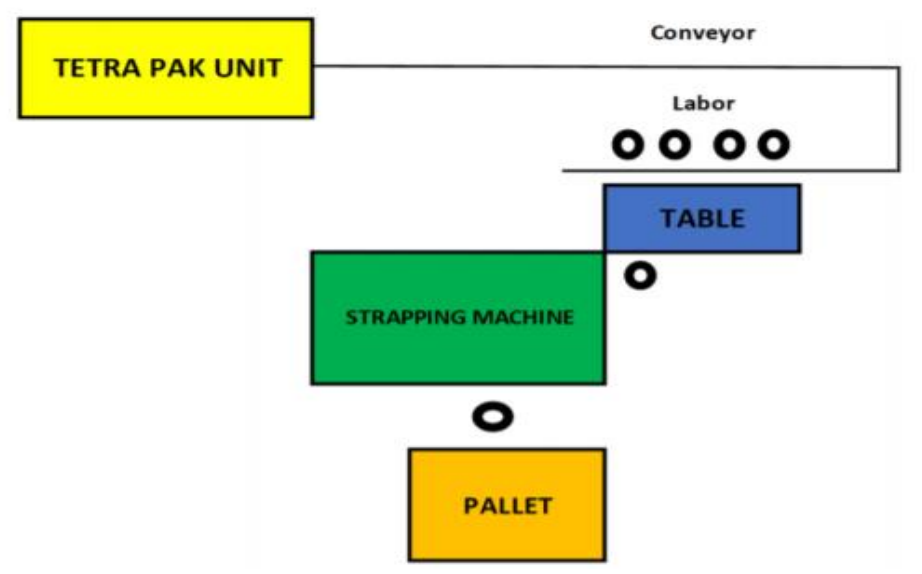

Fig. 4. Production line layout 


\section{Waste Identification}

The seven wastes of lean production are defined; each of these wastes has adverse effects on the line, both on the production level and the energy efficiency level. Table 5 illustrates the wastes found in each process, and the cycle time for each process. The types of waste in the line are as follows:

1. Defects, which were found in the Tetra Pak unit process. Defects occur when the trays close and the cheese is spread and parts of it are squeezed outside the tray. In the cutting process, defects are found as well, after the cheese is cut. In the manual phase, the machine sometimes places more or less cheese than it is required in the pack, which leads to the pack being kicked out of the line during the weight checking process.

2. Over-processing, was identified in the cutting processes. The broken cheese, that fall into the trays are not scrapped but reworked.

3. Inventory, is present in the production line in the form of a long conveyor between the Tetra Pak unit and the Strapping machine.

4. Transportation, which was identified in the Tetra Pak unit. The worker transports the raw ingredients from the preparation room to the Tetra Pak unit manually; the travel distance of the worker to reach the Tetra Pak unit could be reduced. Also the travel distance of the worker from conveyor to Strapping machine could be reduced.

5. Motion, was found in the last manual packaging process where the worker unfolds the cartons. It is possible to unfold the cartons prior to the start of the shift to save time.

6. Waiting, the main wasted time was found in cheese production line, there is a long time waste and line off during the changeover. Single Minute Exchange of Die (SMED) technique is aim to reduce waste in the production system and to standardize machine changeover times. Also, another wasted time during the stoppage in Strapping Machine; final folder; and Labor. Time consume during change the connectors in Tetra Pak unit is considered a wasted time.

Table 5. Wasted times in all processes at the Line 22

\begin{tabular}{|l|c|l|}
\hline \multicolumn{1}{|c|}{ Process } & Time (Minutes.) & \multicolumn{1}{c|}{ Waste } \\
\hline Raw materials & 48 & Unnecessary motion \\
\hline Tetra Pak unit & 83 & Defects, rework, over processing \\
\hline Conveyor & 46 & Defects, inventory \\
\hline Labor & 1712 & Defects, Unnecessary motion \\
\hline Changeover for new batch & 1410 & Waiting \\
\hline Final folder & 286 & Waiting / Rework \\
\hline Strapping machine & 192 & Waiting, Defects \\
\hline
\end{tabular}

\section{Data Analysis for waste}

The seven wastes of lean were analyzed and identified all types of waste in the production line. The two major wastes that were present on the line are defects and waiting. The focus for improving is on the four main types of defects in the line 22; labor; final folder, 
and strapping machine. The fishbone diagram as shown in Fig. 5 represent the main causes of defects. Waiting is also a source of waste which is the waiting time during changeover. The achieved results from analyzing the changeover waste are summarized in the following:

- Changeover time is calculated with $94 \mathrm{~min}$.

- Production rate $=60$ Pack cheese $1 \mathrm{~kg} /$ minute .

- Waste due to one change over time $=5.64$ ton/changeover.

- Number of changeover per month $=15$ changeover/Month.

- Waste due to changeover time/Month $=84.6$ ton/Month.

Table 6 shows the average amounts of each type of waste which shows that the highest amount of waste is due to the labor coming from the manual process, and changeover time. The wasted energy due to presence of waste in the production line is presented in Fig. 6.

Table 6. Effect of lean waste on the energy

\begin{tabular}{|c|c|c|c|c|c|}
\hline & Labor & Changeover & Final folder & Strapping machine & Total \\
\hline Average wasted time Per Shift (Sec/shift) & 1712 & - & 286 & 192 & \\
\hline Average waste Per Shift (Kg/shift) & 1712 & - & 286 & 192 & \\
\hline Average waste Per Month (Ton/Month) & 102.72 & 84.6 & 17.16 & 11.52 & 216 \\
\hline SEC (KWh/Ton) & \multicolumn{5}{|c|}{221.2} \\
\hline Waste energy per Month (KWh /Month) & $22,721.7$ & $18,713.5$ & $3,795.8$ & $2,548.2$ & $47,779.2$ \\
\hline
\end{tabular}

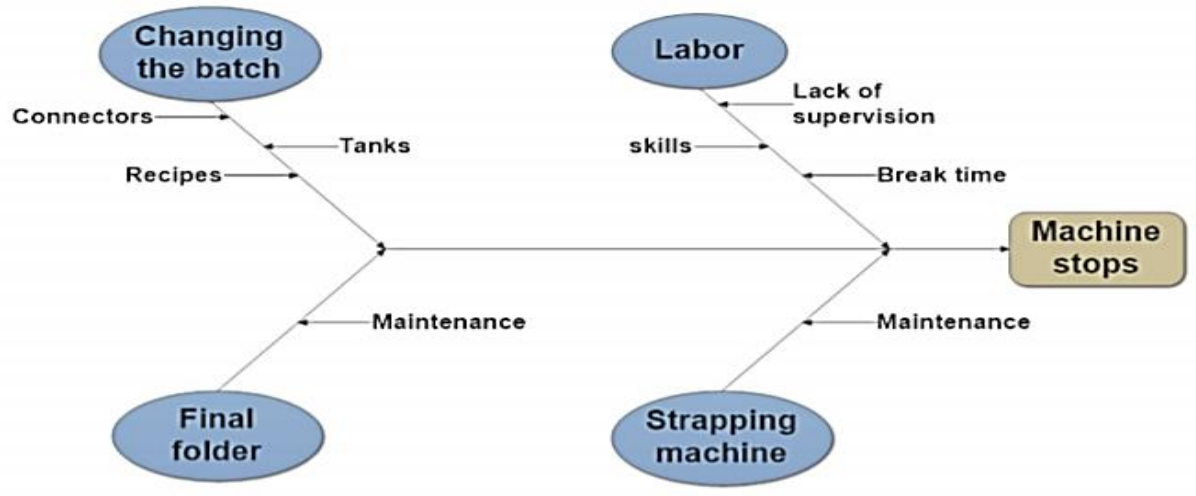

Fig. 5. Cause and effect diagram to define the main causes of waste

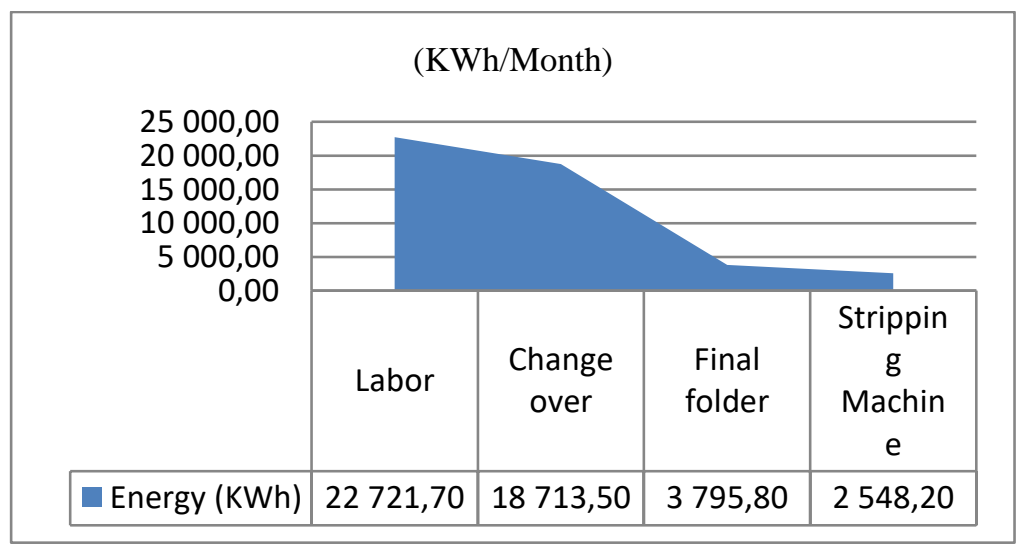

Fig. 6. Energy consumed for the main types of waste in the line 22 


\section{THE RESULTS AFTER IMPLIMENTING LEAN PRODUCTION}

After analyzing and discussed the main kind of waste by using lean tools and cause and effect diagram the achieved results showed that the production line machines need a routine maintenance, cleaning, and redesign for some components to decrease the wasted time, also some training to the workers to follow the guid instructions such as, maintenance, strapping machine and pallet. The improvement includes only the four types of waste; final folder and strapping machine, decrease the wasted time by provides preventive maintenance. Implementing SMED methodology in the production line has a great impact on reducing the changeover time by converting the internal activities to external activity and prepares a tool box before starting the changeover and also uses flexible connectors instead of rigid connectors in Tetra Pak unit machine as shown in Fig. 7. The cardboard machine was the most suitable solution for the labor problem. The machine replaced the job of four workers in the production line, and its function is to put the cheese packs in boxes and get them out as shown in Fig. 8. The new production line layout is presented Fig. 9.

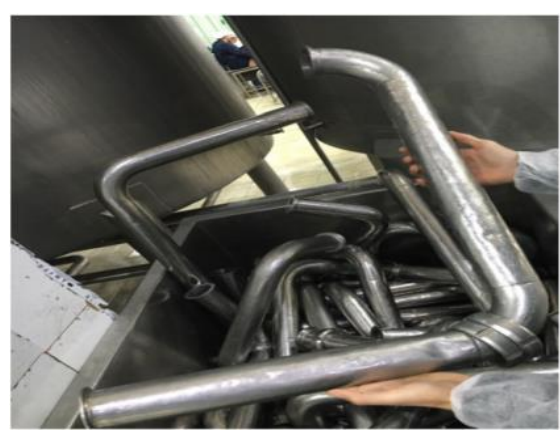

(a) Rigid connectors

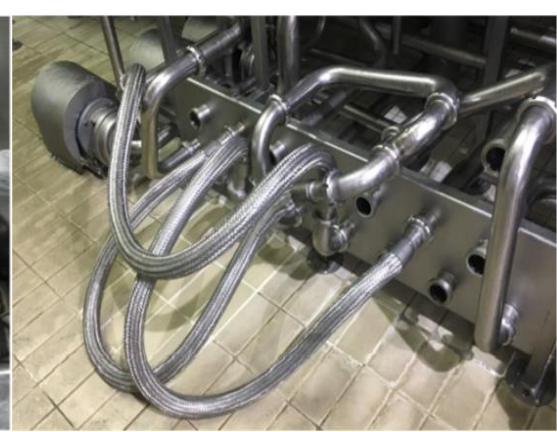

(b) Flexible connectors

Fig. 7. Tetra Pak unit connectors

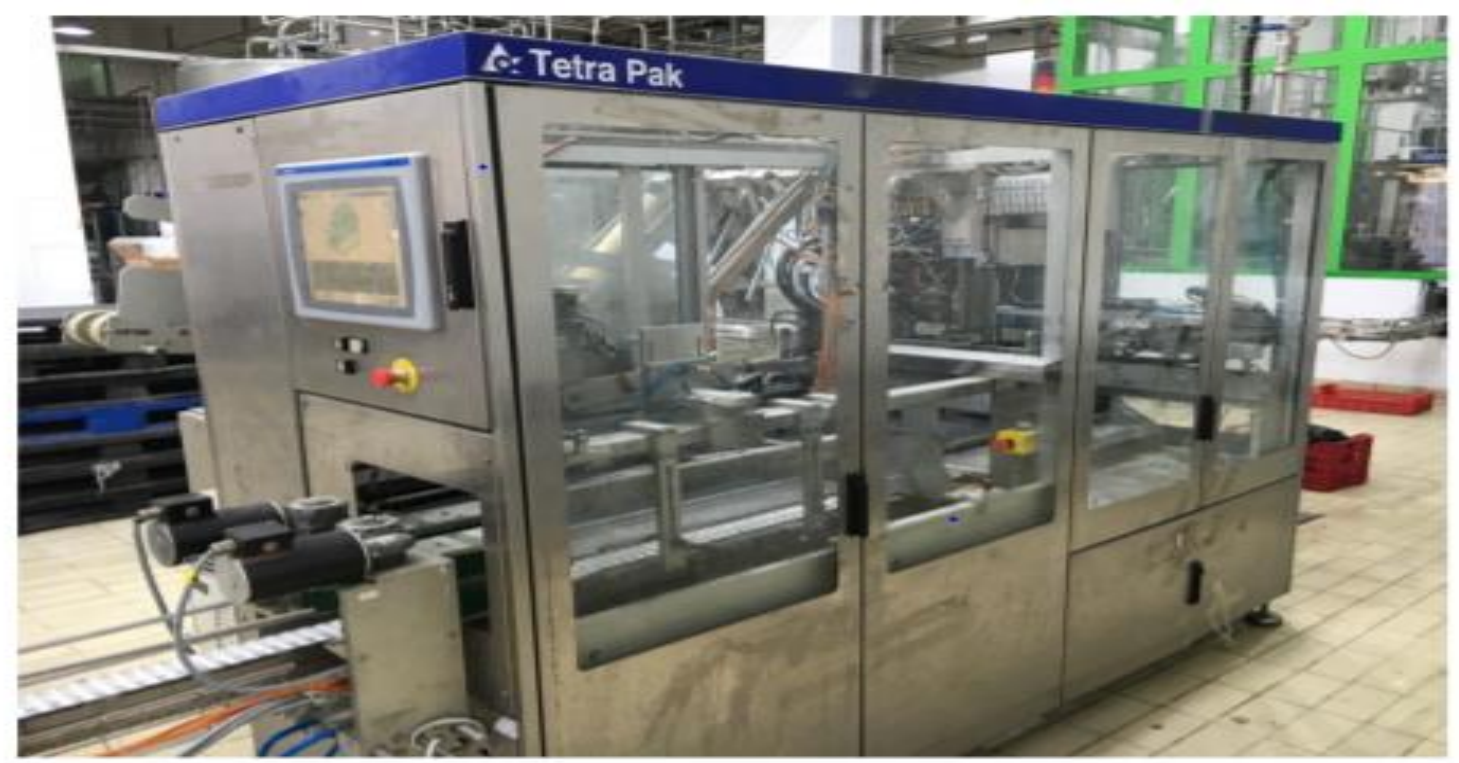

Fig. 8. Tetra Pak Cardboard Packer Machine 
It can be seen from Table 7 that, the labor wasted time is reduced from (1712 to 0 ) sec per shift. Consequently, the final folder wasted time is reduced from (286 to 182) sec per shift. After providing the preventive maintenance the strapping machine wasted time is reduced as well, from (192 to 116) sec per shift. The changeover time reduced from 94 second to 45 second per changeover. Consequently, the total production waste is reduced from (216 to 56.88) ton/Month as shown in Fig. 10. The total wasted energy is reduced from (47,779.2 to 13,510.9) $\mathrm{kWh} /$ Month, as shown in Fig. 11. The achieved results reveal that when the production wastes per month are reduced by $74 \%$, the consumption of energy $(\mathrm{kWh})$ per month is reduced by $4.4 \%$, and the SEC is reduced by $15.1 \%$ as shown in Table 8 .

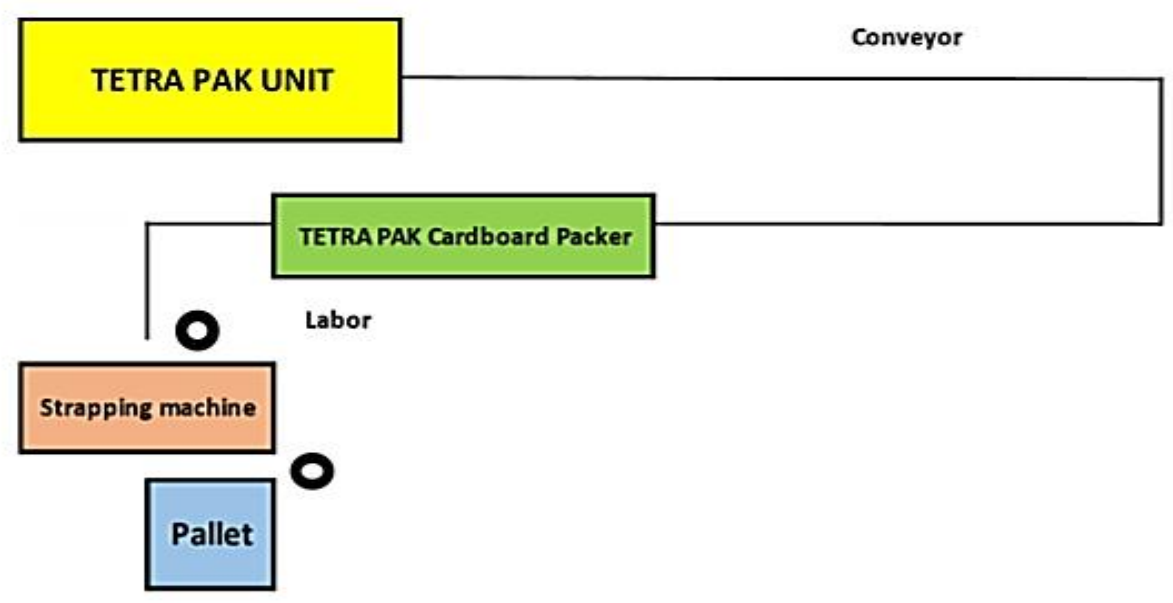

Fig. 9. New production line layout

Table 7. Energy waste after improvements

\begin{tabular}{|l|c|c|c|c|c|}
\hline & Labor & Changeover & Final folder & Strapping machine & Total \\
\hline Average wasted time Per Shift (Sec/shift) & 0 & - & 152 & 116 & \\
\hline Average waste Per Shift (Kg/shift) & 0 & - & 152 & 116 & \\
\hline Average waste Per Month (Ton/Month) & 0 & 45 & 9.120 & 6.96 & 56.88 \\
\hline SEC (KWh/Ton) & \multicolumn{7}{|c|}{221.2} & $13,510.9$ \\
\hline Waste energy per Month (KWh /Month) & 0 & 9,954 & $2,017.3$ & $1,539.6$ & \\
\hline
\end{tabular}

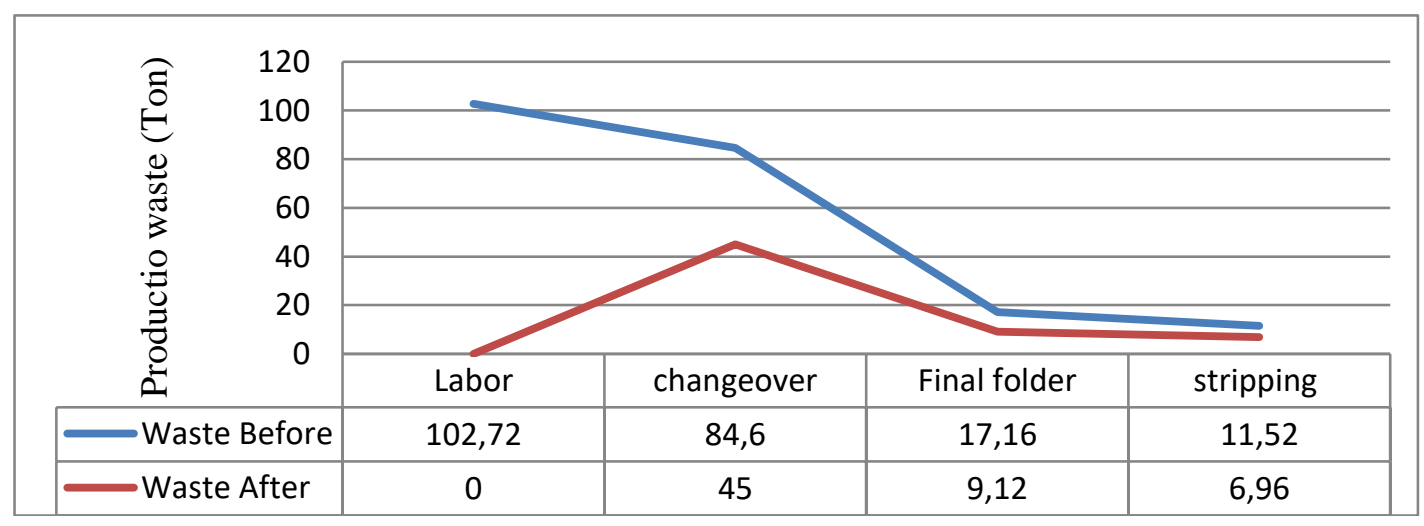

Fig. 10. Change of waste before and after improvement (ton/Month) 


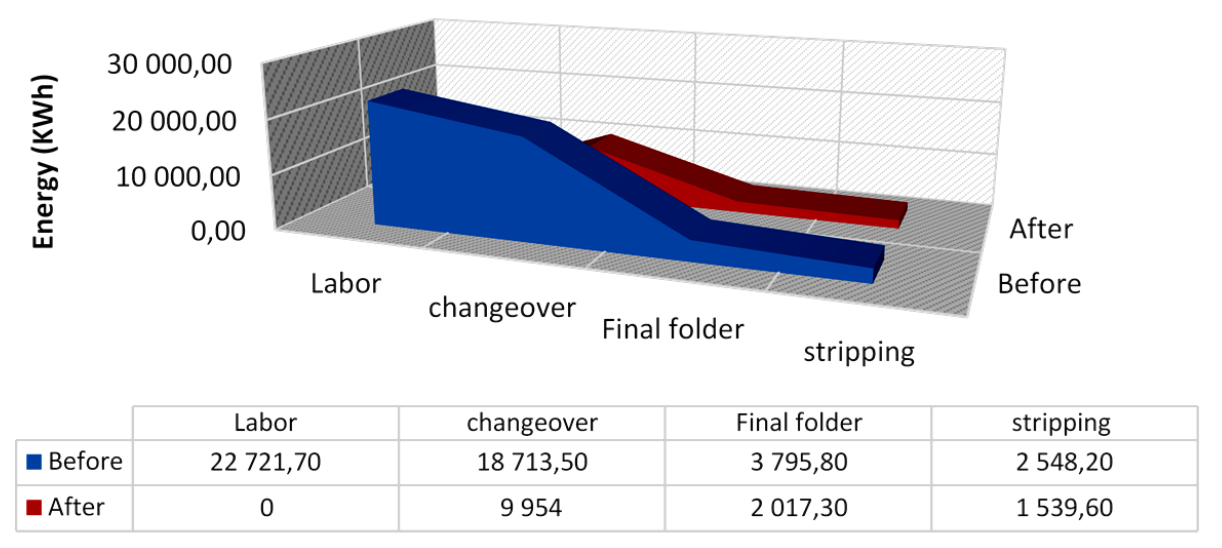

Fig. 11. Change of wasted energy before and after improvement (KWh/Month)

Table 8. Energy saving after improvements

\begin{tabular}{|l|c|c|c|c|}
\hline & $\begin{array}{c}\text { Before } \\
\text { improve }\end{array}$ & $\begin{array}{c}\text { After } \\
\text { improve }\end{array}$ & $\begin{array}{c}\text { Waste } \\
\text { Saving }\end{array}$ & $\begin{array}{c}\text { Waste Saving } \\
(\%)\end{array}$ \\
\hline Production waste (ton /Month) & 216 & 56.88 & 159.12 & 74 \\
\hline energy Waste (KWh /Month) & $47,779.2$ & $13,510.9$ & $34,268.3$ & 72 \\
\hline $\begin{array}{l}\text { Energy Consumption of the line } \\
\text { (KWh/Month) }\end{array}$ & 281,038 & 268,716 & 12,322 & 4.4 \\
\hline SEC (KWh/ton) & 221.2 & 187.9 & 33.3 & 15.1 \\
\hline
\end{tabular}

\section{CONCLUSION}

Implementation of lean methodology has a great impact on improving the energy saving by reducing the specific energy consumption in the organization. The specific energy consumption is a key performance indicator used to measure the efficiency of a production line or a machine in relation to its production. This paper aimed to integrate the specific energy consumption term with lean manufacturing principles. The drivers of the energy consumption were discussed, and the seven wastes within lean perspective were transformed into energy counterparts. The main contribution of this study is to integrate the energy efficiency concept with lean manufacturing methodologies. All kinds of waste of lean approach were defined as energy efficiency perspective. The study will reveal the important of using the energy management model in identifying the area of improvement and the energy saving measure. The most important waste to provide energy efficient manufacturing process is found such as, the labor wasted time is reduced from (1712 to 0) sec per shift. Consequently, the final folder wasted time is reduced from (286 to 182) sec per shift. After providing the preventive maintenance the strapping machine wasted time is reduced as well, from (192 to 116) sec per shift. The changeover time reduced from 94 second to 45 second per changeover. Consequently, the total production waste is reduced from (216 to 56.88) ton/Month. The total wasted energy is reduced from $(47,779.2$ to $13,510.9) \mathrm{kWh} /$ Month. The developed integration method of lean manufacturing tools and energy saving reveals, that the total 
organization wastes are reduced by $74 \%$ per month. Consequently, this waste reduction reduced the energy consumption in the production line by $4.4 \%$ and reduced the SEC by $15.1 \%$.

\section{REFERENCES}

[1] LAWRENCE A., THOLLANDER P., ANDREI M., 2019, Specific Energy Consumption/Use (SEC) in Energy Management for Improving Energy Efficiency in Industry: Meaning, Usage and Differences, Energies, 12, 247.

[2] CAVAllaro F., CIRAOlO L., MAVROTAS G., PECHAK O., 2013, Assessment and Simulation Tools for Sustainable Energy Systems, Green Energy and Technology, 129, 333-356.

[3] LAWRENCE A., KARLSSON M., THOLLANDER P., 2018, Effects of Firm Characteristics and Energy Management for Improving Energy Efficiency in the Pulp and Paper Industry, Energy, 153, 825-835.

[4] LEHTINEN U., TORKKO M., 2005, The Lean Concept in the Food Industry: A Case Study of a Contract Manufacturer, Journal of Food Distribution Research, 36, 57-67.

[5] CHAN D.Y.L., HUANG C.F., LIN W.C., HONG G.B., 2014, Energy Efficiency Benchmarking of Energy-Intensive, Industries in Taiwan, Energy Convers. Manag., 77, 216-220.

[6] SAKR D., ABO SENA A., 2017, Cleaner Production Status in the Middle East and North Africa Region with Special Focus on Egypt, Journal of Cleaner Production, 141, 1074-1086.

[7] KANNAN R., BOIE W., 2013, Energy Management Practices in SME-Case Study of a Bakery in Germany, Energy Conversion and Management, 44/6, 945-959.

[8] MARTÍNEZ C.I.P., 2010, Analysis of Energy Efficiency Development in the German and Colombian Food Industries, International Journal of Energy Sector Management, 4/1, 113-136.

[9] OGUNJUYIGBE A.S.O., AYODELE T.R., OGUNMUYIWA S.M., 2015, Improving Electrical Energy Utilization in Some Selected Nigerian Food and Beverage Industries, Sustainable Energy Technologies and Assessments, 12, $38-45$.

[10] PINERO E., 2009, Future ISO 50001 for Energy Management Systems, http://www.iso.org/iso/iso-focus_200909_p18.

[11] MCKANE A., 2010, Thinking Globally: How ISO 50001-Energy Management Can Make Industrial Energy Efficiency Standard Practice, http://escholarship.org/uc/item/92d8q553.

[12] SCIORTINO M.W.S., 2009, The Importance of Energy Efficiency in Lean Manufacturing: Declaring Energy the Ninth Waste, ACEEE Summer Study on Energy Efficiency in Industry, 113-122.

[13] STERN T.V., 2019, Leaner Six Sigma_Making Lean Six Sigma Easier and Adaptable to Current Workplaces, Productivity Press; 1 st edition.

[14] TSAROUHAS P., 2007, Implementation of Total Productive Maintenance in Food Industry: a Case Study, Journal of Quality in Maintenance Engineering, 13/1, 5-18.

[15] JAIN R.A., 2009, The Implementation of Lean Manufacturing in the UK Food and Drink Industry, International Journal of Services and Operations Management, 548-573.

[16] GONCE A., SOMERS K., 2010, Lean for Green Manufacturing, McKinsey \& Company Report, https://www.mckinsey.com/ /media/mckinsey/dotcom/client_service/Sustainability/PDFs/Lean_Green_Manufact uring.aspx, (Retrieved: 08.08.2018).

[17] LOPES R.B., FREITAS F., SOUSA I., 2015, Application of Lean Manufacturing Tools in the Food and Beverage Industries, Journal of Technology Management and Innovation, 10/3, 120-130.

[18] DUDBRIDGE M., 2011, Handbook of Lean Manufacturing in the Food Industry, Blackwell Publishing Ltd.

[19] UPADHYE N.D., 2010, Lean Manufacturing in Biscuit Manufacturing Plant: A Case, International Journal of Advanced Operations Management, 108-139.

[20] LOZANO J., SAENZ-DÍEZ J.C., MARTÍNEZ E., JIMÉNEZ E., BLANCO J., 2016, Methodology to Improve Machine Changeover Performance on Food Industry Based on SMED, The International Journal of Advanced Manufacturing Technology, 9-12.

[21] IMAI M. KAIZEN G.; 1997, Value Stream Mapping to Reduce the Lead-Time of a Product Development Process, New York, NY: McGraw-Hill.

[22] TYAGI S., CHOUDHARY A., CAI X., YANG K., 2015, Value Stream Mapping to Reduce the Lead-Time of a Product Development Process, International Journal of Production Economics, 160 (November), 202-212. 